\title{
Information Services for the Enterprise Value of Technological Innovation under the Big Data Environment
}

\author{
Wen Xiao ${ }^{a}, \mathrm{Na} \mathrm{Y^{a } n ^ { a , b }}$, and Yunqian Zhang ${ }^{a}$ \\ ${ }^{a}$ Information Resources department, Beijing Institute of Science and Technology \\ Information, Beijing, China \\ bshool of Management, Capital Normal University, Beijing, China \\ *Corresponding author: Wen Xiao, xiaowen8826@126.com
}

\begin{abstract}
With the advent of the era of Big Data, dramatic change took place in the field of information resources. This paper describes the information needs of enterprise technology innovation at first, and then analyzes the Big Data technology used for technological innovation information service's core values, finally discusses the coming challenges under the Big Data environment for technological innovation information service up.
\end{abstract}

Keywords: Information services, big data, technological innovation

\section{Introduction}

October 2011, McKinsey in the research report "Big Data: innovation, competition and productivity under a new field", officially used the term "Big Data", firstly proposed "Big Data" era has arrived [1]. Big Data has four "V" characteristics, namely Volume, Velocity, Variety, Value. Like cloud computing, "Big Data" is a hot topic for people in recent years. From 2013 "Big Data" popular in the world to use "big data" calculated "House of Cards" has become the most popular American TV in 2014, Big Data has quickly entered the stage of practical application of theoretical research.

Under the Big Data environment, in the process of technological innovation of enterprises, the amount of data demand, generation, and storage presents a rapidly growing trend, businessoriented technological innovation information service from requirements to model has undergone tremendous changes. In order to meet the advent of the era of Big Data, how to provide efficient data management and a new information service model for technological innovation, has a very important significance. From the technological innovation needs, proposed to build a large data-based information service model.

\section{Under the Big Data Environment, Information Needsof Enterprise Technology Innovation}

Technological innovation refers to the production, including the development of new technologies, or the application of existing technology innovation. Science is the foundation of technology, technology is the source of industries, technological innovation, built on the basis of scientific justification was found above, while industrial innovation primarily on the basis of technological innovation [2]. With the global economic integration and the increasingly fierce market competition, technological factor is the core of enterprises to participate in market competition, technological innovation has become a key determinant of 
business survival. In fact, technological innovation is a risky activity. According to product innovation experts, each eleven "seriously pondered", the idea or concept, only there can be developed, one point their production, and ultimately only one can be successful.

Information services through research users, user organizations, service organizations, will be valuable information to users, and ultimately help users to solve the problem of an information management activities. Fast and efficient information services is becoming improve their core competitiveness of the key factors. Under the Big Data environment, technological innovation has created a demand of new information services.

\subsection{Conception and project-oriented information needs}

Technological innovation is a market demand, and ultimately to the commercialization process of the market in the form of feedback. Market demand for the industry technological innovation is the source of power. The idea of the project is the foundation stage of business and technological innovation activities, determines the direction of innovation activities. In the conception and project stage, the main task of business is technological innovation projects industry market demand trends analysis, project feasibility analysis, environmental analysis and innovation policies and regulations, assess their own potential competitor analysis. Information needs of enterprise technology innovation ideas and project stage involves many aspects, such as market information and industry-related technology trends at home and abroad, domestic and international macro-economic trends, competitors, technological strength and market dynamics demand for similar products, as well as with domestic outside technical innovation policy, technological development policy, economic policy and other related laws and regulations and other environmental information.

Big Data era has brought a huge, chaotic information, although innovation to meet the enterprise information for the amount of data information, but also to the idea and the project stage enterprises brought some problems, such as due to market demand, competition, user location information and other intelligence to understand not timely, comprehensive, causing the effect of technology innovation strategic planning, development and implementation of innovations are not satisfied with the effect of consequences, leading to strategic expansion, failed investment decisions. Enterprises should take full advantage of big data, data mining, data analysis, semantic processing technology in the industry, the market, not only need to collect real-time current technological development of new technologies, products and technology industry demand, market competition and other information, but also according to market trends and needs, analyze the potential market demand, advance research and development. In the policy environment, technological innovation activities of enterprises not only to comply with innovative trends at home and abroad, but also relying on state support. From the scientific and technological innovation-oriented point of view, companies need to recognize the innovation environment, the situation, the development direction and other information at home and abroad; enjoy state support from the point of view, companies need real-time control changes in technology, industrial policy, and enjoy collecting taxes, financial incentives information. 


\subsection{Research and development-oriented information needs}

Research and development stage is the core stage of technological innovation activities, technological innovation is the key to the success of the decision stage. The main tasks include raised in line with market demand, technological innovation and industry research programs, the formation of the production system in line with the requirements of technology development programs, developed in line with corporate decision-making system requires new technologies, new products, new materials research and development program. In the research and development stage, the information needs of enterprise technology innovation and similar products mainly involves technical information, market performance, the development trend of information related to product trends, with domestic and foreign advanced technology, the level of developments related to the production process-related information, and domestic and international design standards of technical standards information related to the product, as well as the enterprise's own existing level of technology, production capacity, technological innovation strength and other information.

Under the Big Data Environment, faces the complex information, companies may not be able to find useful information, leading companies in the development process of new technologies, new products, due to a lack of intelligence and information support, generate new technical route is not clear, product development, program design unreasonable, the new technology is not fully developed understanding of such issues. So, companies need to gather a lot of journal articles, patents results, technical standards and other intelligence information, screening of useful data, information, research and development of open information channel, to build with independent intellectual property rights, in line with the design standards of technology and products provide sources of information, to ensure the smooth conduct research and development, to avoid duplication of research results with others, and improve enterprise technological innovation.

\subsection{For the application and promotion of information needs}

Application and promotion are the final stage of technological innovation, but also test whether technological innovation into economic interests stage, the main task is to develop corporate marketing strategies and product promotion advertising strategy, technological innovations into domestic and international markets. In the application and promotion stage, the information needs of enterprise technology innovation, including the sales channels, user preferences, market reaction and other related marketing information, and personnel structure, product market competition and other related information on the distribution and advertisingrelated information.

Big Data era, we just like being in the ocean of data, how to marketing, advertising and other means to highlight the corporate information technology innovations, it is very difficult in the massive data. So, enterprises need to collect technical strength competitors and potential competitors, production scale, competitive strategy and other aspects of information, combined with the characteristics and advantages of their products to develop marketing strategies; domestic and foreign enterprises and by learning advanced experience of marketing, increase product information transmission route for enterprises to open channels of advertising. Effectively avoid market risks, enhance competition, increase the rate of return on investment, improve market competitiveness through technological innovation. 


\section{Big Data Technology Used in Business-oriented Technological Innovation Information Service's Core Values}

Big Data is not just a concept of the amount of data, including high-speed mass data acquisition, processing and analysis technology architecture and technical process of extracting the value of the meaning. The core value of Big Data is that for massive data storage and analysis. Compared to other existing technology, big data, "cheap, fast, optimization" comprehensive cost of these three areas is optimal [3].In today's knowledge economy, the level of technological innovation capability of enterprises directly determines the survival and development of enterprises.

Enterprise technological innovation as the main goal is the information needs of enterprise technology innovation, continuous improvement through technological breakthroughs or the original technology and products into practical productive forces. The current Big Data technologies and applications focused on data analysis, data warehousing, etc., mainly for OLAP (Online Analytical System), From a technical point of view, mainly including MR, MPP and other mainstream bulk data processing and to Storm, as the mainstream memory database, real-time data stream processing. Applications big data technology, combined with technological innovation systematic, comprehensive and creative features, can provide more valuable services for the enterprise. (Fig. 1)

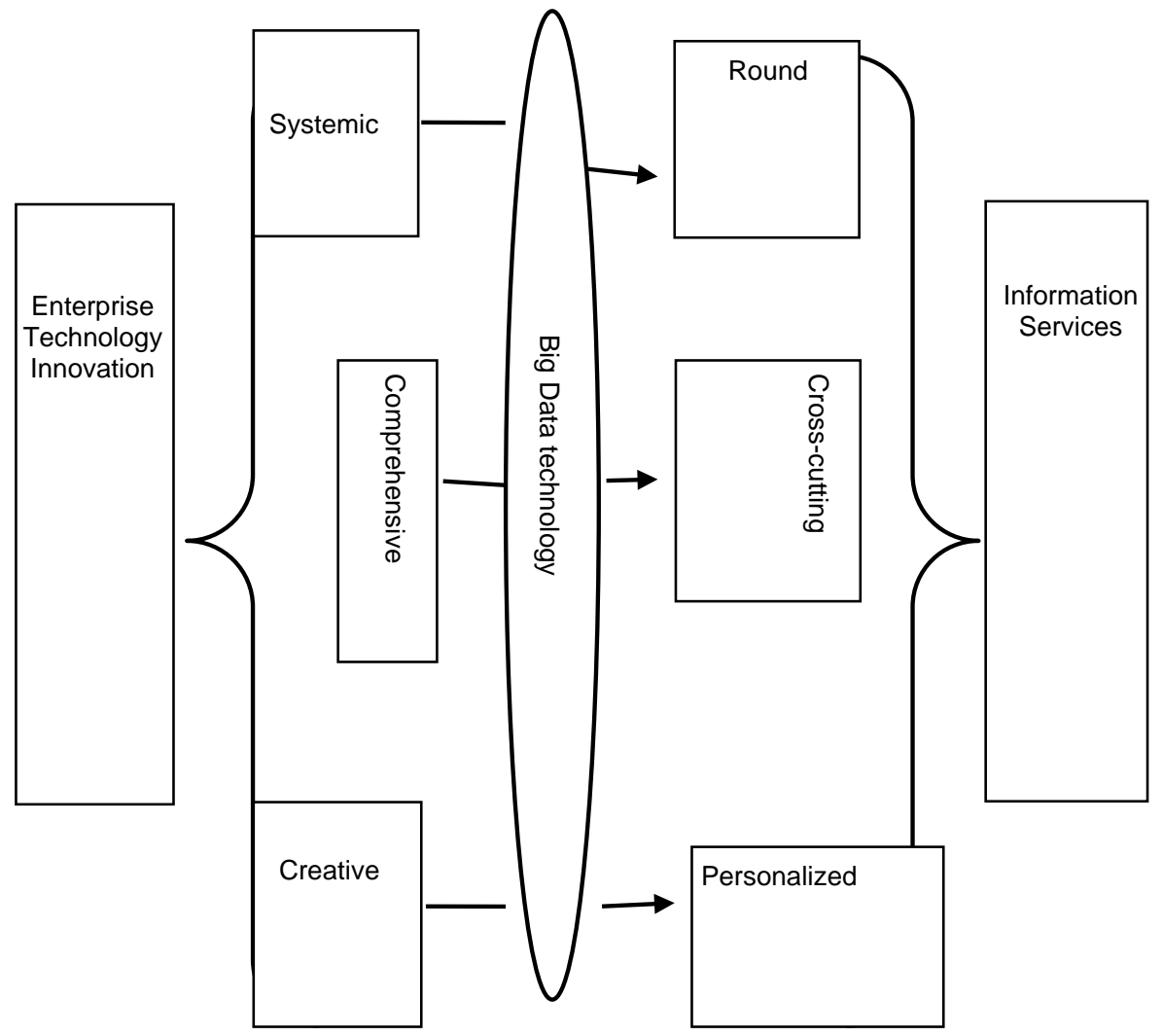

Fig. 1- Big Data technology used in business-oriented technological innovation information service's core values

\subsection{For systemic features of enterprise technology innovation, providing a full range of information services}

Technological innovation is a development of new technologies or improving existing technology activities, covering a new technology, new products from research and 
development to enter into the market and the application of a series of activities involving strategic planning, technology development, production, marketing, all aspects of finance, human resources and other business activities. Throughout the entire process of information services that can ensure the smooth progress of technological innovation.

In the era of Big Data, the data is becoming one of the most important assets of the enterprise, business development, decision-making, marketing and other activities are no longer with personal experience or intuition, but through data analysis to complete. Application of technological innovation can get real-time big data technology, comprehensive information services. In the early planning stages, you can use TopSy, Storm and other real-time search engine can reach 1 million copies per document indexing, through real understanding of the industry trends, project feasibility studies, so that technological innovation can quickly into the core of the research and development stage; in the development stage mid, you can use Google's Map Reduce and raised the company's Teradata Aster Data technology can achieve parallel processing of massive data, comprehensive performance data mining, real-time tracking progress of research and development related to technology, in-depth analysis, mining vast amounts of information, Get tacit knowledge; in the market late stage, can be performed by the views, voting and other social data on Twitter, Facebook, micro letters, micro blogging and other social tools generated analysis to capture user preferences and other information to predict market trends, to develop an accurate marketing strategy.

\subsection{For a comprehensive technological innovation features provide cross-domain information associated services}

Technical innovations include not only the meaning of technology, including the contents of multiple aspects of the business, management and so on. In the process of technological innovation may involve multiple industries, or the existence of cross multiple disciplines in a technology. So, in addition to master the core technology of information, companies also need to understand the knowledge of related disciplines and interact with related fields.

Big Data technology allows inter-professional collaboration can produce mutual benefits1+1>2. To communications carriers and broadcasting operators, for example, communications carriers have a communication system analysis capabilities and user experience of mobile Internet users the ability to use while on the broadcast of radio and television operators unidirectional transmission, lack of customer perception. Combination of both user preferences can be reflected at different angles, with big data analytics platform, communications carriers and broadcasting operators to explore cooperation with the customer-centric insight precise cross-service capabilities and product promotion, and so on. Big data can be cross-sectoral, multi-disciplinary, cross-business data analysis and mining. With large data provided massive amounts of data associated with cross-border information services, to ensure that technological innovation has a higher accuracy and professionalism. On one hand, collaboration involving many fields, real-time data stream processing can make timely and effective interaction between the various areas of the information service platform, to establish good coordination mechanism to ensure the efficient conduct of technological innovation; on the other hand, involves multidisciplinary, information service platform of massive data, you can expert database, the database can get a lot of cross-disciplinary information resources to meet the needs of technology innovation knowledge. 


\subsection{Technological innovation for creative features to provide personalized information services}

Technological innovation instead of copying others' research, but through the introduction, digestion, absorption process, the use of original things to create something new. This means that technological innovation must be creative. In the era of Big Data, updated technical information is constantly changing business needs for technical innovation related information also with changes in the external environment and internal progress and change. Personalized information services, can grasp the specific needs of enterprises, push the appropriate information in a timely manner, provide information support for technological innovation.

Taobao shopping cart auto cruise function is to provide personalized services through a typical big data technology. For buyers, Taobao can according to each user's favorites, shopping categories, search history, browsing history data, etc., to provide consumers with personalized services, including a similar recommendation, showing people who bought the same type of products of interest other commodities; for sellers, Taobao free open shopping cart data, sellers buyers see later put products into your cart, you can direct propaganda discounts to consumers, according to statistics, the "shopping cart marketing" to promote the shopping cart merchandise turnover rate increased by 2.5 times. Technological innovation for creative features can also use big data technology to provide personalized information services. Business-oriented information service model including the characteristics of the database, SDI, tracking services. According to business needs and expectations, customrelated information services. In the process of technological innovation, using data mining techniques to identify hidden business preferences and related information needs, real change policy information services, tools, personalized push services.

\section{Big Data Challenge to the Business-oriented Technology to Bring Innovative Information Services}

November 2013, the National Bureau of Statistics and Ali, Baidu and other 11 companies signed a strategic cooperation framework agreement to promote big data applications in government statistics. Big Data problems will deepen reform and opening facing our country and the environment, transport, education, health care and other aspects of the real challenges, play an important strategic significance. Big Data in the birth of the social, technical, scientific and economic changes, but also to business-oriented technological innovation information service brings information security is no security, recognizing the existence of bias, lack of data processing capabilities, and many other challenges. (Fig. 2) 


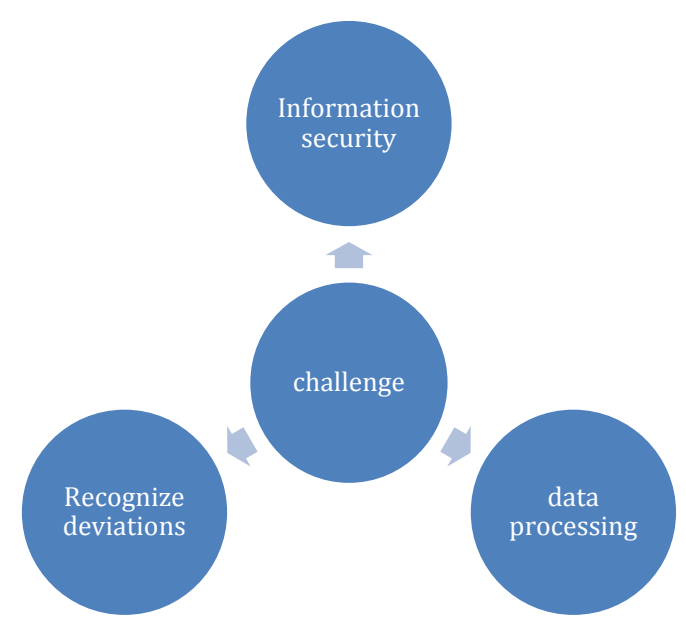

Fig. 2 - Big data challenge to the business-oriented technology to bring innovative information services

\subsection{Information security is not guaranteed}

The rapid development of Internet technology allows businesses easier access to information, but it may make the enterprise technological innovation information service to face the problem of privacy protection. Technological innovation can be a commercial application of the technology innovation, innovation can also be applied legally obtained, the development of new technology or the other party has entered the public domain technology to create market advantage. For our business, completely independent research in the form of technological innovation is a minority, the majority of companies need to carry out independent research and development of innovation on the basis of imitation draw.

Learn to imitate others in terms of technology, the collection and use of data as well as large application process large data platform, are likely to involve national information security, corporate trade secrets, privacy and other citizens. Once the privacy issues involved, there may be unable to obtain the information, or even require legal liability. Japan's largest mobile communications operator NTT DoCoMo, early in 2010 before it began planning the use of big data. DoCoMo adopt national uniform data collection, integration in the form of not only focus on collecting the user's own age, gender, address and other information, and the production of fine form, requires the user to fill out more detailed information to conduct business, you can get the country's system data. But, NTT DoCoMo big data development still in the planning stages, because NTT DoCoMo not resolve customer privacy issues. Visible, to be applied to large data-oriented technological innovation information service provision needs to be made clear from the legislative level for large data collection and use, the development of technical standards and operating large data specification; and build large data and information security systems strengthen the supervision of key areas, sensitive data, build healthy and orderly large data environment.

\subsection{Recognize deviations}

Big Data has gradually become a buzzword now, whether it is IT practitioners, businesses or professionals, always like to talk about the topic of big data, but it has a very different view. According to a survey report Connotate shows that 49 percent of American senior 
departmental data aggregation will be defined as the aggregation of large data all external and internal pages of data, $16 \%$ of people are by definition its enterprise storage and management of large amounts of internal data ; $7 \%$ of people think that this is data and network-related data and content services to operate commercial services to their [4].

Understanding of big data applications in technological innovation deviations include two cases: First, as the main technological innovation of SMEs, many believe that big data is Google, Amazon, Taobao and other companies will be applied to the technology, without considering the introduction of big data to the enterprise technological innovation; Second, the provider of information services for the data collected should give companies much, how to calculate the cost to develop data analysis problem still exists in doubt. Awareness of the existence of large data deviation will lead to big data technology can't get further promotion, or generate large data utility to reduce other consequences.

\subsection{Insufficient data processing}

Due to the large amount of data has a huge data, the type of data range, low-value density data, the processing speed of the characteristics of enterprise technology innovation to provide information services need to have the ability to match the data processing, including data analysis talent, high-capacity storage capacity, high-speed information transmission capacity to support rapid analysis, processing capacity and density of valuable data and so on. In fact, the provider of information services on the processing power of big data many deficiencies exist.

First, the lack of professionals big data aspects of the era of extremely large data requirements for data analysts, only large data specialized personnel only have the skills to develop analytical applications model predicted that, in addition to data extraction requires IT technician and industry experts work together to establish reasonable data structure; Secondly, the major data systems are not unified data model, but the data processing involves a variety of techniques, only with structured data processing capabilities, can't support unstructured, semi-structured data processing; Thirdly, the amount of data is growing faster than the storage capacity, information service providers will face TB-level data sets, traditional database, network drives can't carry such information; Finally, Hackers either organizational skills, tools of crime, modus operandi or covert extent are continued to improve with the development of the Internet, Internet-based massive data leaked to how to avoid a no-fat molecule is in the collection, storage, transport and other links important issues.

\section{Conclusions}

Technical innovation is the pillar upon which the survival of power and sustainable development, the establishment of technical innovation in the information technology, digital is the trend on the basis of big data era of enterprise development. Currently, the country is still at large data preliminary stages of development, but its social value, commercial value has gradually emerged. Enterprises can use big data technology to provide comprehensive, cross-domain correlation, personalized information services for the company's technology innovation, and enhance ability to obtain information and market adaptability, improve their core competitiveness. Despite the challenges of big data will bring some information about the lack of security, recognizing the existence of bias, lack of data processing capabilities, 
such as the challenges many companies, such as technological innovation information service, however, I believe that as long as the full value of big data, and actively respond to large data challenges, you can make big data to provide better information services for enterprises, technical innovation will eventually translate into power and the rapid development of the competitiveness of enterprises.

\section{References}

1. Big data: The next frontier for innovation, competition, and productivity, http://www.mckinsey.com/insights/mgi/research/technology_and_innova tion/big_data_the_next_frontier_for_innovation (15. 6. 2012)

2. D. He, Technology innovation, business innovation, enterprise innovation and all aspects of innovation, http://wenku.baidu.com/link?url=B4E42E7d_67sUbJMXc4P1afsB_ndymytIDgkCLkDh1Sla8ghh8Vpt1TU1De6DTUs1Qo mOVSHzet0fpiHK5je34qRjhFxbbbrBMjgj41B3S (22. 12. 2009)

3. What is the most core value of data? http://www.thebigdata.cn/Hadoop/10803.html (25. 6. 2014)

4. Connotation: Big data application situation of enterprises, http://www.199it.com/archives/21624.html. (20. 7. 2012 )

5. The first year 2013 data: data across all walks of life, http://cloud.chinabyte.com/vertical/329/12816829.shtml. (25. 12. 2013 )

6. G. Liu, H. Wang, J. Wu, Analysis of Competitive Intelligence Development in the Era of Big Data, Knowledge ,learning\& Management. 2 (2013) 105-111.

7. P. Zhang, Information Demand and Information Service in Enterprises' Technological Innovation, Information Research. 1 (2015) 81-83. 